\title{
Organizational Culture and its Implications on Infection Prevention and Control
}

\author{
Baral $\mathrm{R}^{1}$ \\ ${ }^{I}$ Department of Pathology, Patan Academy of Health Sciences, Lalitpur, Nepal
}

\author{
Keywords: \\ IPAC; \\ Nosocomial infections; \\ Hygiene; \\ MRSA.
}

\begin{abstract}
The hospital acquired infections are becoming common in our hospitals lately. These infections are difficult to treat and maybe life threatening. Hospital acquired infection can be minimized or eradicated by good Infection Prevention and Control guidelines and good hand hygiene practices. The success of Infection Prevention and Control guidelines program in any hospital is largely impacted by the organizational culture. In any health care setting the management is challenged by the organizational culture to change of any kind. Where implementation of Infection Prevention and Control guidelines program is easily implemented in some hospitals it is very difficult in others. Moreover, hand hygiene is not only biomedical practice but also has more behavioral factors.
\end{abstract}

\section{INTRODUCTION}

Nosocomial infections are those acquired in or associated with hospitals. They are also known as hospital-acquired infections (HAIs). The usual definition of a hospitalacquired infection is one that was not present or incubating when the patient was admitted to a hospital or healthcare facility; where there is doubt, a cut-off period of 48 hours after admission is used. HAIs continue to constitute a major challenge to healthcare institutions, in terms of patient mortality and morbidity as well as unnecessary financial expenditure. ${ }^{1}$

\section{Correspondence:}

Dr. Reetu Baral, MBBS, MD

Associate Professor

Department of Pathology, Patan Academy of Health Sciences.

Email:reetubaral@pahs.edu.np.
A lot of studies have shown that an effective infection control program in a hospital will reduce the incidence of HAIs. Even though Infection Control deals with biomedical practices it is essentially a behavioral science. Over the past decade, numerous change tools have become available aimed at achieving better Infection Prevention and Control (IPAC) compliance. ${ }^{2}$ The success of IPAC program in some hospitals and failure in others despite the literature based evidence of its effectiveness in controlling HAIs and very low cost in implementing it points towards the organizational culture. The Geneva model has been the basis of most international initiatives aimed at improving hand hygiene compliance. ${ }^{4}$ However, attempts to introduce it within other healthcare institutions, using a similar methodology, have often failed to replicate success. ${ }^{5,6}$

IPAC principles have been used very sparsely in the hospitals 
in Nepal. Majority of the hospitals, both government and private, do not have an IPAC committee/ department nor professionals trained in IPAC. Though data are not available in these hospitals, many cases of HAIs are seen which has unnecessarily increased the morbidity and mortality of the patients. Moreover, in Nepal the patients have to pay for the treatment from their own pocket since the medical insurances are not present. The increased cases of HAIs will definitely increase the financial, psychological and social burden to the patients and their families. If only the hospital managers and healthcare professionals encouraged the use of hand rubs and hand hygiene most of the HAIs can be avoided.

\section{ORGANIZATIONAL CULTURE}

A group of people sharing a common goal form an organization. By working towards these common goals they form common beliefs and values, which is unique to that organization. An organizational culture is a learned entity. Organizational culture (OC) may range from simply as "this is the way we do it here" to highly complex basic assumptions, external adaptations and internal integration. The latter is evident in Schein's definition of OC as 'the pattern of basic assumptions that a given group has invented, discovered, or developed in learning to cope with its problems of external adaptation and internal integration, and that have worked well enough to be considered valid, and, therefore to be taught to new members as the correct way to perceive, think, and feel in relation to those problems. ${ }^{7}$ Organizational culture is not only what the members have learned but also what they believe. It also incorporates perceptions as well as practices shared within the organization rather than the values held by the individuals. Hofstede et al. define OC as 'collective mental programming' that distinguishes the members of as organization from another.8 They represent OC using an onion model (fig. 1). At its core are the values, unwritten codes and beliefs held by the members of the organization. These intangibles are then layered by the visible practices: rituals (collective activities which are considered socially essential), heroes (individuals who possess characteristics which are admired and deemed important) and symbols (the most externally visible component incorporating the gestures, objects, words or acts that distinguish the members of that organization from others). ${ }^{8}$

\section{PROFESSIONAL CULTURE}

The organizational culture becomes more complex when different hierarchical levels are considered. Within the hospital the physicians, nurses and other healthcare professionals have gained their professional status over a long curse of time. By creating and controlling the professional status these professionals control the destiny of the organization. The $\mathrm{OC}$ becomes meaningful when changes come to the organization. When changes are threatening, individuals and groups may challenge the ideological basis of the organization. Members who are benefiting from the current culture may try to legitimate their actions and status of the organization power structure by reference to tradition. ${ }^{9}$ In these situations these group may attempt to ensure that their group interests are well represented at all times.

\section{ORGANIZATIONAL CULTURE AND INFECTION PREVENTION AND CONTROL}

Success of IPAC depends on the multiple management systems, which is strongly influenced by the $\mathrm{OC}$ of the institute. The vital point in an institute is the presence of well- trained staffs. It has been proven in many studies that increased number of HCAIs has been associated with overcrowding of the patients, high staff turnover, under staffing, heavy bed occupancy and overcrowding. ${ }^{10-12}$

\section{MULTI-DISCIPLINARY TEAM}

There are evidences that healthcare institutes that promote a culture of teamwork develop more effective IPAC program. The formation of multi-disciplinary clinical teams has shown to reduce rates of hospital-acquired pneumonia in intensive care units. Inappropriate prescription of unnecessary antibiotics was significantly reduced when multidisciplinary team was involved which led to marked reduction of infections caused by extended beta-lactamase (ESBL) - producing Enterobacteriaceae. ${ }^{13,14}$

\section{ROLE OF LEADERSHIP}

Strong leadership is needed starting from the top management level to the lower level is needed for successful IPAC programs. Recent study has shown that hospitals with effective leadership showed better hand hygiene compliance and improved PPE practices compliance than in those institutions where the role of leadership is negligible. ${ }^{15}$ Excessive strong step down of the leadership will have a negative impact on how the nurses work increasing the level of dissatisfaction in the job satisfaction and responsiveness of the employees. The best way to shape the OC is to take full ownership of the institution reviewing the policies, internal structures, rules and regulations.

\section{FOLLOWING THE ORGANIZATIONAL POLICIES}

Any healthcare institution requires a compliance of organizational rules and regulations by its employees. According to Cabana et al. physicians do not stick to the guidelines of the institution due to a) lack of awareness, (b) lack of familiarity, (c) lack of agreement and (d) lack of self-efficacy. ${ }^{16}$

\section{JOB SATISFACTION AND COMMITMENT}

A consistent relationship between low staff satisfaction and increased incidents of mortality is seen, whatever the cause of mortality maybe. A positive job satisfaction and 


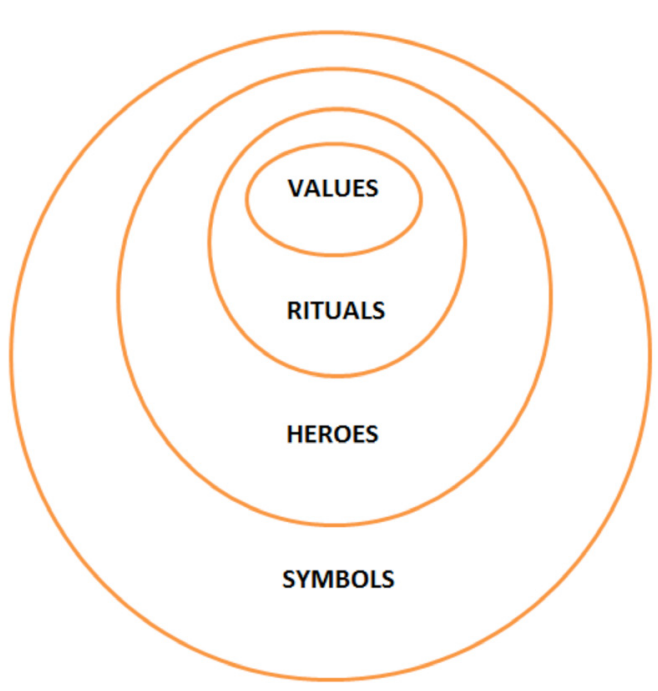

Figure 1: Hofstede's representation of organizational culture

good adherence to IPAC policies have been seen in few studies. $^{12,17}$

\section{COMMUNICATION GAP}

Communication gap between the management of the healthcare institute, staff and patients is one of the major reasons for lack of quality improvement in IPAC. In contrast to this an efficient multi organizational communication will show high level of performance hence reducing the morbidity and mortality associated with HAIs.

\section{BEHAVIOR CHANGE}

In investigating the cultural impact on changes in behavior of medical personnel, Turnell and White proposed the 'stages of change theory' as a powerful theoretical framework for both educators and targeted participants..$^{18} \mathrm{In}$ their application of the six-step model of change, as applied to hand hygiene, the authors highlight that educational programmes may fail unless the training provided also addresses the issues of psychological preparedness of medical staff. In addition to dissemination of information, the aim of infection prevention control (IPC) education should be to empower participants to believe in their ability to bring about the required change through their behavior.

The self-efficacy theory designates four modalities to influence behavior change.49 These include: (a) performance enactment which focuses on modifying beliefs about the person's ability to perform the desired behavior, (b) vicarious learning which modifies self-efficacy by watching others, (c) verbal persuasion which modifies behavior through significant interaction with others, and (d) emotional arousal which promotes the idea that more relaxed, less aroused participants would be more likely to be aware of the need to consider performing hand hygiene. ${ }^{19}$
Change forces individuals to move away from their comfort zone, so it is often undesirable. It should therefore be no surprise to find varying degrees of non-compliance to change in IPC behavior. All sorts of resistance will be observed if the new behavior is not perceived by individuals as rewarding enough to have it adopted. Saint et al. attribute lack of adherence to IPC policies and procedures either to 'active resistors' or to 'organizational constipators' ${ }^{20}$ Active resistance is described as the lack of complete certainty by relevant authorities on their commitment to introduce new practices. On the other hand, organizational constipators' are defined as individuals who are generally mid-to-high level executives and who prevent or delay certain actions without overtly and publicly showing active resistance. These (professional) individuals resist change by increasing the effort required to implement evidence-based practices.

\section{AUDITING}

There has been increased pressure to use more extensive quality indicators measures in healthcare, especially infection rates. ${ }^{21}$ For any hospital HCAI rates have been used as an effective marker for levels of staffing, training, management failure, reliability and resilience. ${ }^{22}$

\section{CHANGE IN THE ORGANIZATION CULTURE}

Larson et al. focused on a top level administrative initiative using a framework for changing OC among staff on handwashing. ${ }^{23}$ They used a multifaceted approach to make an effective change e g. dissemination of key messages, marketing approach, education interventions, audit and feedback and opinion of experts. The study concluded that there was change in OC as well as improvement in both process (frequent handwashing) and outcome (vancomycinresistance enterococci incidence). What emerges from this study is that strategies aimed at achieving long-term improvement in IPC performance need to be multi-modal in order to both reflect and address the multidimensionality of the structure and the dynamic of OC. ${ }^{24}$ It confirms that OC is indeed a complex and important factor in altering IPC compliance, which needs to be empirically investigated in different scenarios. ${ }^{25}$

The reported behavior is often significantly different from observed behavior. What people say is different from what they actually really do. Not surprisingly, low correlation is often reported between self- reported and observed compliance of IPC practices such as hand hygiene. ${ }^{26}$ Leadership, for instance, plays an important supportive role; nevertheless it is not clear what exact style of leadership will promote or discourage compliance in IPC behavior. Strategy formulation is a cultural development and all attempts at OC change should be viewed as strategic changes.

\section{CONCLUSION}

It seems reasonable to postulate that $\mathrm{OC}$ should be a highly 
relevant factor in achieving more effective IPC performance. Simple correlations such as 'a strong culture leads to good performance' have not yet been scientifically supported. On the other hand, there appears to be a consensus that $\mathrm{OC}$ is historically and socially constructed, holistic and difficult to change. 9

Change management literature promotes the idea that collective behavior requires breaking away from group patterns or habits, or - more explicitly - replacing existing behavioral patterns with new ones. To modify OC one needs to introduce a series of intermediating variables such as mind-set, values, attitude, knowledge and practices, amongst others. These new variables will eventually help in addressing the variance in the relationship between $\mathrm{OC}$ and IPC-compliant behavior. It is therefore crucial to understand the most effective ways of addressing cultures that hinder(or promote) correct IPC implementation; after all IPC implementation deals as much with behavioral science as it does with biomedical. This knowledge base is notably lacking. We urgently need more data and quality information about effective and generalizable strategies that can achieve OC change and lead to improved IPC interventions.

\section{REFERENCES}

1. Kraker ME, Wolkewitz M, Davey PG, Grundmann H. Clinical impact of antimicrobial resistance in European hospitals: Excess mortality and length of hospital stay related to Methicillin-Resistant Staphylococcus aureus bloodstream infections. J Antimicrob Chemother. 2011 Feb;66(2):398-407. Crossref

2. World Health organization. WHO Guidelines on Hand Hygiene in Health Care, Geneva. World Health organization, 2009. ISBN-13: 978-92-4-159790-6

3. Dellit TH, Owens RC, McGowan JE et al. Infectious diseases Society of America and the Society for Healthcare Epidemiology of America Guidelines for Developing an Institutional Program to Enhance Antimicrobial Stewardship. Clin Infect Dis2007;44:159-77. Crossref

4. Pittet D, Hugonnet S, Harbarth S et al. Effectiveness of a hospitalwide programme to improve compliance with hand hygiene. Lancet 2000;356:1307-12. Crossref

5. Giannitsioti E, Athanasia S, Antoniadou A et al. Does a bed rail system of alcohol-based handrub antiseptic improve compliance of health care workers with hand hygiene? Results from a pilot study. Am J Infect Control 2009;37:160-3. Crossref

6. Abela N, Borg MA. Impact on hand hygiene compliance following migration to a new hospital with improved resources and the sequential introduction of World Health Organization recommendations. Am J Infect Control 2012;40:737-41. Crossref

7. Schien E. Organisational culture and leadership. San Francisco:JosseyBass; 1995. 464p.

8. Hofstede G, Hofstede GJ, Minkov M. Cultures and organisations: software of the mind. New York: McGraw-Hill; 2010.129p.

9. Bloor G, Dawson P. Understanding professional culture in organizational context. Organ Stud 1994;15:275-95. Crossref

10. Housner JA. A model for evaluating the context of nursing care delivery. J Nurs Admin 2003;33:39-47. Crossref

11. Griffiths P, Renz A, Hughes J, Rafferty AM. Impact of organization and management factors on infection control in hospitals: a scoping review. J Hosp Infect 2009;74:1-14. Crossref
12. Borg MA. Bed occupancy and overcrowding as determinant factors on the incidence of MRSA infections within general ward settings. J Hosp Infect 2003;54:316-318. Crossref

13. Kay J, Ashline V, Erickson D. Critical care bug team: a multidisciplinary team approach to reducing ventilator-associated pneumonia. Am J Infect Control 2000;28:197-201. Crossref

14. Saizy-Callaert S, Causse R, Furham C, Le Path MF, Theobault A, Chouaid C. Impact of a multidisciplinary approach to the control of antibiotic prescription in general hospital. J Hosp Infect 2003;53:177182. Crossref

15. Sinkowitz-Cochran RL, Burkitt KH, Cuerdon T, et al. The associations between organizational culture and knowledge, attitudes and practices in multicenter Veterans Affairs quality improvement initiative to prevent methicillin-resistant Staphylococcus aureus. Am J Infect Control 2012;40:138-143. Crossref

16. Cabana MD, Rand CS, Powe NRP, et al. Why don't physicians follow clinical practice guidelines? A framework for improvement. JAMA 1999;282:1458-65. Crossref

17. Aiken LH, Clarke SP, Cheung RB, Sloane DM, Silber JH. Educational levels of hospital nurses and surgical patient mortality. JAMA 2003;290:1617-1623. Crossref

18. Turnell EP, White GL. Using behaviour change theories to enhance hand hygiene behaviour. Educ Health (Abingdon) 2005;18:80-84. Crossref

19. De Bono. G. Heling. M.A. Borg. Organizational culture and its implications for infection prevention and control in healthcare institutions. J Hosp Infect 2014;86:1-6. Crossref

20. Saint S, Kowalski CP, Banaszak-Holl J, Forman J, Damschroder L, Krein SL. How active resisters and organisational constipators affect health-care acquired infection prevention efforts. Joint Comm J Qual Imag 2009;35:239-46.

21. Sevdalis N, Undre S, Henry J et al. Development, initial reliability and validity testing of an observational tool for assessing technical skills of operating room nurses. Int J Nurs Stud 2009;46:1187-93. Crossref

22. Pittet D, Ste' phane F, Hugonnet S, Akakpo C, Souweine B, Clergue F.Hand-cleansing during postanesthesia care. Anesthesiology 2003;99:530-5. Crossref

23. Larson EL, Early E, Cloonan P, Sugrue S, Parides M. An organizational climate intervention associated with increased handwashing and decreased nosocomial infections. Behav Med 2000;26:14-22. Crossref

24. Eaker R, Gonzales D. Leading in professional learning communities. Natl Forum Educ Admin Supervision J 2007;24:6-13

25. Aiken CB, Scott PK. The CEO's role in leading transformation. Manag Quart 2007;48:30-57.

26. O'Boyle CA, Henley SJ, Larson E. Understanding adherence to hand hygiene recommendations: the theory of planned behaviour. Am J Infect Control 2001;29:352-60. Crossref 